\title{
Adubação foliar (S, Mn e Zn) em diferentes estádios fenológicos do feijoeiro comum
}

\section{irrigado}

\author{
Foliar fertilization (S, Mn and $\mathrm{Zn}$ ) at different phenological stages of irrigated common bean \\ Fertilización foliar (S, Mn y Zn) en diferentes estados fenológicos de frijol común de regadío
}

Recebido: 28/07/2021 | Revisado: 05/08/2021 | Aceito: 10/08/2021 | Publicado: 14/08/2021

\author{
Willian Carvalho Sulino \\ ORCID: https://orcid.org/0000-0003-4127-9020 \\ Instituto Federal de Educação, Ciência e Tecnologia Goiano, Brasil \\ E-mail: williancsulino@outlook.com \\ Wilian Henrique Diniz Buso \\ ORCID: https://orcid.org/0000-0003-0568-2605 \\ Instituto Federal de Educação, Ciência e Tecnologia Goiano, Brasil \\ E-mail: wilian.buso@ifgoiano.edu.br
}

\begin{abstract}
Resumo
O feijoeiro é uma planta exigente em nutrientes devido ao seu sistema radicular superficial e ciclo curto. A deficiência de manganês e zinco, pode reduzir a atividade metabólica devido à demanda em processos fisiológicos. O enxofre pode limitar a produtividade da cultura. Objetivou-se avaliar o desempenho do feijoeiro comum sob diferentes doses de fertilizante foliar aplicado em dois estádios fenológicos. $\mathrm{O}$ delineamento utilizado foi o DBC com quatro repetições e os tratamentos foram 5 doses de adubo foliar $\left(0 ; 0,250 ; 0,500 ; 0,750\right.$; e $\left.1 \mathrm{~L} \mathrm{ha}^{-1}\right)$ em dois estádios fenológicos de aplicação (V4 e R5). Como fonte de Mn, Zn e S foi usado o fertilizante foliar GRAIN SET ${ }^{\circledR}$. Após 102 dias da semeadura foi realizado a colheita de forma manual, e os grãos secos ao ar a 13\% de umidade. As variáveis analisadas foram: altura de planta $(\mathrm{m})$, número de vagem por planta, número de grãos por vagem, massa de 1000 grãos (g) e produtividade (kg ha ${ }^{1}$ ). Em relação ao estádio fenológico V4 e R5, somente a variável número de vagens por planta obteve diferença significativa. Para massa de mil grãos e produtividade houve efeito significativo. A produtividade ficou entre $3437,59 \mathrm{e}$ $5543,58 \mathrm{~kg} \mathrm{ha}^{-1}$. Esse aumento na produtividade se explica devido a presença de zinco no adubo foliar. A dose de $0,5 \mathrm{~L}$ $\mathrm{ha}^{-1}$ para massa de mil grãos obteve melhor desempenho de peso $(285,40 \mathrm{~g})$.
\end{abstract}

Palavras-chave: Cultivar pérola; Phaseolus vulgaris L; Enxofre; Zinco; Manganês.

\begin{abstract}
The bean plant is a nutrient-demanding plant due to its shallow root system and short cycle. Manganese and zinc deficiency can reduce metabolic activity due to the demand on physiological processes. Sulfur can limit crop productivity. This study aimed to evaluate the performance of common bean under different doses of foliar fertilizer applied at two phenological stages. The design used was the DBC with four replications and the treatments were 5 doses of foliar fertilizer $\left(0 ; 0.250 ; 0.500 ; 0.750\right.$; and $\left.1 \mathrm{~L} \mathrm{ha}^{-1}\right)$ in two phenological stages of application (V4 and R5). As a source of $\mathrm{Mn}, \mathrm{Zn}$ and S, the foliar fertilizer GRAIN SET® was used. After 102 days of sowing, harvesting was carried out manually, and the grains were air-dried at $13 \%$ humidity. The variables analyzed were: plant height (m), number of pods per plant, number of grains per pod, mass of 1000 grains $(\mathrm{g})$ and yield $\left(\mathrm{kg} \mathrm{ha}^{-1}\right)$. In relation to the phenological stages V4 and R5, only the variable number of pods per plant had a significant difference. For mass of one thousand grains and yield there was a significant effect. The productivity was between 3437.59 and $5543.58 \mathrm{~kg}$ ha ${ }^{-1}$. This increase in productivity is explained by the presence of zinc in the foliar fertilizer. The dose of $0.5 \mathrm{~L} \mathrm{ha}^{-1}$ for mass of one thousand grains obtained the best performance at a weight $(285.40 \mathrm{~g})$.
\end{abstract}

Keywords: Cultivate pearl; Phaseolus vulgaris L; Sulfur; Zinc; Manganese.

\section{Resumen}

La planta de frijol es una planta que requiere nutrientes debido a su sistema radicular poco profundo y ciclo corto. La deficiencia de manganeso y zinc puede reducir la actividad metabólica debido a la demanda de los procesos fisiológicos. El azufre puede limitar la productividad de los cultivos. El objetivo de este estudio fue evaluar el comportamiento del frijol común bajo diferentes dosis de fertilizante foliar aplicado en dos etapas fenológicas. El diseño utilizado fue el DBC con cuatro repeticiones y los tratamientos fueron 5 dosis de fertilizante foliar (0; 0.250 ; 0.500; 0.750; y 1 L ha-1) en dos etapas fenológicas de aplicación (V4 y R5). Como fuente de Mn, Zn y S se utilizó el fertilizante foliar GRAIN SET®. Después de 102 días de siembra, la recolección se realizó manualmente y los granos se secaron al aire a $13 \%$ de humedad. Las variables analizadas fueron: altura de planta (m), número de vainas por planta, número de granos por vaina, masa de 1000 granos (g) y rendimiento (kg ha-1). En relación a los estadios fenológicos V4 y R5, solo la variable número de vainas por planta tuvo una diferencia significativa. Para masa de mil 
granos y productividad hubo un efecto significativo. La productividad estuvo entre 3437,59 y 5543,58 kg ha-1. Este aumento de productividad se explica por la presencia de zinc en el fertilizante foliar. La dosis de $0.5 \mathrm{~L}$ ha-1 para masa de mil granos obtuvo el mejor desempeño con un peso $(285.40 \mathrm{~g})$.

Palabras clave: Cultivar perla; Phaseolus vulgaris L; Azufre; Zinc; Manganeso.

\section{Introdução}

Por ser uma cultura de ciclo curto, o feijoeiro (Phaseolus vulgaris) possibilita o plantio em até três safras durante o ano. A na primeira safra ou das águas, colhida entre os meses de dezembro e março; segunda safra ou da seca, colhida entre os meses de abril a julho e a terceira safra ou de inverno, colhida entre os meses de agosto a novembro (Silva \& Wander, 2013).

Na primeira safra nacional de feijão de 2021, foram colhidas cerca de 1.003,5 toneladas entre feijão-comum cores, feijão-comum preto e feijão-caupi, em uma área de 904,3 mil ha ${ }^{-1}$. As lavouras de segunda safra já foram implantadas e somam cerca de 1.437,6 mil hectares semeados, com os feijões do tipo comum cores, comum preto e caupi, com expectativa de produção estimada em 1.325,7 mil toneladas do grão. Já para terceira safra área destinada para o plantio é de 556,1 mil ha-1, com estimativa de produção 775,9 mil toneladas do grão. Desta forma a área total será de $2.898,0$ mil ha $^{-1}$, com produção estimada de 3.105,1 mil toneladas do grão, em todo o Brasil (Conab, 2021).

O feijoeiro é uma planta exigente em nutrientes devido ao seu sistema radicular superficial e ciclo curto. Os nutrientes devem estar disponíveis no local e tempo adequado, para que a planta possa desenvolver de modo a atingir o máximo potencial (Rosolem \& Marubayashi, 1994). A exigência nutricional das culturas, em geral, torna-se mais intensa com o início da fase reprodutiva, geralmente após a quarta semana de sua germinação, sendo mais crítica na época de formação das sementes, quando consideráveis quantidades de nutrientes são translocadas. Essa maior exigência se deve ao fato de os nutrientes serem essenciais à formação e ao desenvolvimento de novos órgãos de reserva (Carvalho \& Nakagawa, 2000).

A deficiência de micronutrientes, especialmente a de manganês e zinco, pode reduzir a atividade metabólica devido à demanda em processos fisiológicos, como componentes de enzimas essenciais e também comprometer a manutenção estrutural e a integridade funcional das membranas, o manganês está relacionado à formação da lignina (Marschner, 1995), além de ser essencial para respiração dos vegetais e para metabolismo do nitrogênio (Marschner, 2012). O manganês atua efetivamente em algumas reações enzimáticas catalisadas por metais as que requerem magnésio. Clorose entre nervuras das folhas e nas margens indicam deficiência (Malavolta, 2006).

Plantas cultivadas em condição de deficiência de zinco, geralmente, produzem sementes com baixo conteúdo e concentração desse nutriente e quando semeadas em solo deficiente, as plântulas são menos vigorosas refletindo em baixo rendimento na colheita (Prado, et. al., 2007).

Em relação ao enxofre, embora não seja objeto de preocupação na maioria dos programas de adubação, sua deficiência pode limitar a produtividade da cultura (Furtini Neto, et al., 2000).

O enxofre é exigido pelo vegetal para formação de aminoácidos e proteínas, para a fotossíntese e para resistência a baixas temperaturas. É importante também para nodulação e desenvolvimento radicular (Epstein \& Bloom, 2006). Quando existe limitação no suprimento de S, a aplicação de doses elevadas dos demais nutrientes, principalmente $\mathrm{N}$, $\mathrm{P}$ e K, pode não resultar em aumento de produtividade, devido ao desequilíbrio nas relações N/S e P/S na planta (Cruciol, et al., 2006).

Com base no exposto, objetivou-se com este trabalho avaliar o desempenho do feijoeiro comum cultivado com diferentes doses de fertilizante foliar aplicado em dois estádios fenológicos. 


\section{Metodologia}

A pesquisa foi realizada no Município de Ceres-GO, na fazenda Experimental do Instituto Federal Goiano Campus Ceres, cuja as coordenadas geográficas são S $15^{\circ} 21^{\prime} 00^{\prime}$, W $49^{\circ} 35^{\prime} 57^{\prime}$ e com altitude média de 564 m, sob regime de pivô central.

O delineamento experimental foi em esquema fatorial 5x2, com quatro repetições, a área do experimento foi de 0,4 ha 1, e os tratamentos utilizados foram cinco doses de adubo foliar $\left(0 ; 0,250 ; 0,500 ; 0,750\right.$; e $\left.1 \mathrm{~L} \mathrm{ha}^{-1}\right)$ em dois estádios fenológicos de aplicação. Os estádios fenológicos foram o V4 (três folhas trifolioladas totalmente desenvolvidas) e R5 (desenvolvimento dos primeiros ramos secundários e o surgimento dos primeiros botões florais) conforme Embrapa (2018). Utilizou-se o fertilizante foliar GRAIN SET® que possui 4\% de manganês, 3,14\% de enxofre e 1,50\% de zinco, a aplicação do fertilizante foliar foi feito com o uso de um pulverizador agrícola costal de 201, com bico tipo leque, as aplicações eram realizadas no fim tarde, devido as temperaturas serem amenas e não haver vento na área evitando a deriva do fertilizante.

O preparo de solo foi realizado com uma gradagem intermediaria e nivelamento do solo. A adubação foi efetuada de

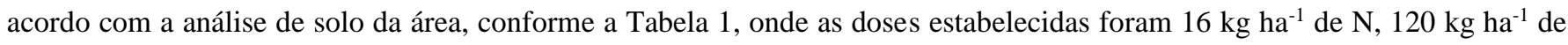
$\mathrm{P}_{2} \mathrm{O}_{5}$ e $40 \mathrm{~kg} \mathrm{ha}^{-1}$ de $\mathrm{K}_{2} \mathrm{O}$. A cultivar Pérola foi empregada para este estudo, com espaçamento de $0,5 \mathrm{~m}$ entre linhas e com distribuição de 12 sementes por metro, a semeadura ocorreu no dia 14/05/2019.

Tabela 1. Resultado das análises química e granulométrica do solo, na profundidade de $0-20 \mathrm{~cm}$, antes da instalação do experimento.

\begin{tabular}{|c|c|c|c|c|c|c|c|c|c|c|c|c|}
\hline Areia & Silte & Argila & $\mathrm{pH}$ & M.O. & $\mathrm{Mg}$ & $\mathrm{Al}$ & $\mathrm{H}+\mathrm{AL}$ & K & $\mathrm{T}$ & $\mathrm{K}$ & $\mathrm{P}^{*}$ & $\mathrm{~V}$ \\
\hline $\mathrm{g} \mathrm{kg}^{-1}$ & & & $\left(\mathrm{H}_{2} \mathrm{O}\right)$ & $\mathrm{g} \mathrm{dm}^{-3}$ & $\mathrm{cmol}_{\mathrm{c}} \mathrm{dm}^{-3}$ & & & & & $\mathrm{mg} \mathrm{dn}$ & & $\%$ \\
\hline 482 & 40 & 478 & 5,82 & 22 & $3,85 \quad 1,94$ & 0 & 3,8 & 0,56 & 10,15 & 180 & 30 & 62,57 \\
\hline
\end{tabular}

*Extrator Mehlich-1. Fonte: Arquivo Pessoal (2019).

O feijoeiro ao atingir o estádio fenológico V4 (terceiro trifólio totalmente desenvolvido), recebeu uma adubação em cobertura de $\mathrm{N}$, e a fonte empregada foi a ureia com (45\% de N) com dose de $130 \mathrm{~kg} \mathrm{ha}^{-1} \mathrm{de} \mathrm{N}$.

A irrigação foi realizada via pivô central, onde o manejo se dava através do uso do tanque classe A e o Kc da cultura, alterando desta forma a lâmina aplicada de acordo com o desenvolvimento da planta (Embrapa, 2013).

Após 102 dias da semeadura foi realizada a colheita de forma manual. Para a debulha dos grãos utilizou-se uma trilhadeira tratorizada, e após secagem ao ar livre até atingirem a umidade de 13\%. As variáveis analisadas foram: altura de planta (m), número de vagem por planta, número de grãos por vagem, massa de 1000 grãos $(\mathrm{g})$ e produtividade $\left(\mathrm{kg} \mathrm{ha}^{-1}\right)$.

Os dados obtidos foram submetidos à análise de variância, as médias foram comparadas pelo teste de Tukey a 5\% de significância e análise de regressão das variáveis estudadas em função das doses de fertilizante foliar, utilizando o software R.

\section{Resultados e Discussão}

Observa-se que não ocorreu interação significativa entres as fontes de variação. Assim, as variáveis foram analisadas de forma individual. De acordo com as análises de regressão das variáveis em função das doses de fertilizante foliar ocorreu ajuste ao modelo quadrático para as variáveis massa de 1000 grãos e produtividade (Tabela 2). 
Tabela 2. Quadrados médios das fontes de variação aplicação de fertilizantes foliar (AFF) e épocas de aplicação (EA) e da interação (AFF x EA) para as características de altura de planta (AP), número de vagens por planta (NVP), número de grãos por vagem (NGV), massa de 1000 grão (MMG) e Produtividade (PROD).

\begin{tabular}{|c|c|c|c|c|c|}
\hline Fonte & $\mathrm{AP}(\mathrm{m})$ & NVP & NGV & MMG (g) & PROD $\left(\mathrm{kg} \mathrm{ha}^{-1}\right)$ \\
\hline \multicolumn{6}{|l|}{ Variação } \\
\hline AFF & $0,0245^{\mathrm{ns}}$ & $52,2780^{\mathrm{ns}}$ & $0,1357^{\mathrm{ns}}$ & $1150,7431^{* *}$ & $5264850,6^{* *}$ \\
\hline EA & $0,1135^{\mathrm{ns}}$ & $8,1125^{* *}$ & $0,0075^{\mathrm{ns}}$ & $768,8554^{\mathrm{ns}}$ & $805000,63^{\mathrm{ns}}$ \\
\hline $\mathrm{AFF} \times \mathrm{EA}$ & $0,1091 \mathrm{~ns}$ & $5,4668^{\mathrm{ns}}$ & $0,1683^{\mathrm{ns}}$ & $670,7323^{\mathrm{ns}}$ & $491328,35^{\mathrm{ns}}$ \\
\hline $\mathrm{CV}(\%)$ & 16,83 & 15,01 & 10,31 & 7,64 & 12,65 \\
\hline \multicolumn{6}{|l|}{ Regressão } \\
\hline Linear & $0,28045^{\mathrm{ns}}$ & $0,280450^{\mathrm{ns}}$ & $0,040972^{\mathrm{ns}}$ & $1108.02^{\mathrm{ns}}$ & $13173407^{\mathrm{ns}}$ \\
\hline Quadrática & $0,06654^{\mathrm{ns}}$ & $0,066544^{\mathrm{ns}}$ & $0,40679 \mathrm{~ns}$ & $2974,68^{* *}$ & $2879548^{* *}$ \\
\hline
\end{tabular}

** significativo a 5\%. ${ }^{\text {ns }}$ não significativo. Fonte: Arquivo Pessoal.

Conforme as Tabelas 2 e 3 observa-se que não houve efeitos significativos para as variáveis a altura de planta (AP) os valores para esta variável ficaram entre 1,36 a 1,52 m, para número de grãos por vagem (NGV) apresentou valores entre 4,88 a 5,21 de acordo com as doses aplicadas (Tabela 3).

Em relação aos estádios fenológicos V4 e R5, somente a variável NVP obteve diferença significativa, em que a aplicação de fertilizante foliar no estádio fenológico R5 $(15,22)$ proporcionou incremento médio de 2,33 vagens por planta em comparação a aplicação no V4 (12,89), conforme Tabela 3. Esta diferença pode estar relacionada com a ação dos nutrientes presente no fertilizante foliar em aumentar o pegamento de flores quando aplicado no estádio fenológico R5. Segundo Oliveira et al. (2015) que utilizaram fertilizante foliar (B, Cu e Mn) no feijoeiro verificaram que estes nutrientes também promoveram maior pegamento de flores e redução no abortamento de vagens cuja média foi de 10,79 vagens por planta.

Bevilaqua et al. (2002), utilizando pulverização foliar observaram aumento no número de vagens por planta e número de sementes por vagem, quando aplicados na fase de floração. O autor justifica, que a causa deste aumento foi devido ao fato da adubação foliar poder aumentar ou manter a concentração de nutrientes nas folhas, no período de enchimento de grãos. Nessa fase, a absorção de nutrientes pelas raízes é reduzida e que esta prática aumenta o conteúdo de nutrientes na planta e o metabolismo formador de estruturas reprodutivas promovendo assim, aumento na produtividade.

Para as variáveis massa de mil grãos (MMG) e produtividade (PROD) houve diferença significativa. Os maiores valores foram para a dose de $0,5 \mathrm{~L} \mathrm{ha}^{-1}$ e a menor para testemunha. Já para a produtividade os melhores valores foram para a dose de $0,75 \mathrm{~L} \mathrm{ha}^{-1}$ e a menor para a testemunha (Tabela 3 ). 
Tabela 3. Altura de plantas (AP), número de vagem por planta (NVP), número de grãos por vagem (NGV), massa de mil grãos (MMG) e produtividade (PROD) do feijoeiro sob as doses de adubação foliar em estádios fenológicos diferentes.

\begin{tabular}{|c|c|c|c|c|c|}
\hline $\begin{array}{l}\text { Doses } \\
\left(\mathrm{L} \mathrm{ha}^{-1}\right)\end{array}$ & $\begin{array}{l}\text { AP } \\
(\mathrm{m})\end{array}$ & NVP & NGV & $\begin{array}{c}\text { MMG } \\
(\mathrm{g})\end{array}$ & $\begin{array}{l}\text { PROD } \\
\left(\mathrm{kg} \mathrm{ha}^{-1}\right)\end{array}$ \\
\hline 0 & $1,36 \mathrm{a}$ & $12,81 \mathrm{a}$ & $5,02 \mathrm{a}$ & $252,51 \mathrm{~b}$ & $3437,59 \mathrm{~b}$ \\
\hline 0,25 & $1,24 \mathrm{a}$ & $13,22 \mathrm{a}$ & $5,15 \mathrm{a}$ & $266,93 \mathrm{~b}$ & $3802,63 \mathrm{~b}$ \\
\hline 0,5 & $1,34 \mathrm{a}$ & $14,18 \mathrm{a}$ & $5,15 \mathrm{a}$ & $285,40 \mathrm{a}$ & $4482,98 \mathrm{~b}$ \\
\hline 0,75 & $1,50 \mathrm{a}$ & $15,26 \mathrm{a}$ & $5,21 \mathrm{a}$ & $274,30 \mathrm{~b}$ & $5543,58 \mathrm{a}$ \\
\hline 1 & $1,52 \mathrm{a}$ & $14,83 \mathrm{a}$ & $4,88 \mathrm{a}$ & $267,43 \mathrm{~b}$ & $4596,08 \mathrm{~b}$ \\
\hline \multicolumn{6}{|l|}{ Época } \\
\hline V4 & $1,37 \mathrm{a}$ & $12,89 \mathrm{~b}$ & $5,07 \mathrm{a}$ & $273,70 \mathrm{a}$ & $4230,71 \mathrm{a}$ \\
\hline R5 & $1,42 \mathrm{a}$ & $15,22 \mathrm{a}$ & $5,10 \mathrm{a}$ & $264,93 \mathrm{a}$ & $4514,44 \mathrm{a}$ \\
\hline $\mathrm{CV}(\%)$ & 16,83 & 15,01 & 10,31 & 7,64 & 12,65 \\
\hline
\end{tabular}

Médias seguidas por letras distintas na coluna diferem entre si pelo Teste de Tukey ao nível de 5\% de probabilidade. Fonte: Arquivo Pessoal (2019).

Oliveira, Pelá \& Pelá (2017), trabalhando com inoculação com Rhizobium e adubação foliar com molibdênio nas doses de 0; 50; 100 e $150 \mathrm{~g} /$ ha $^{-1}$, observaram que houve um aumento significativo na massa de 1000 grãos e na produtividade do feijão comum de acordo com o aumento nas doses de 100 e $150 \mathrm{~g} /$ ha $^{-1}$. Já para Frasca et al. (2020), não houve incremento nos valores em função dos tratamentos realizados com 3,5\% Zn + 2,5\% Mo + extrato de algas Eklonya e N - 7,0\%; Zn - 8,5\% acetato de Zn amoniacal, pra massa de 1000 grãos. Os mesmos autores observaram produtividade entre $2197 \mathrm{~kg}$ ha ${ }^{-1}$ e $3039 \mathrm{~kg}$ ha $^{-1}$, com a dose de $\mathrm{N}-7,0 \% ; \mathrm{Zn}-8,5 \%$ - acetato de $\mathrm{Zn}$ amoniacal. O presente trabalho obteve valores maiores de produtividade que ficaram entre 3437,59 $\mathrm{kg} \mathrm{ha}^{-1}$ na dose de $0 \mathrm{~L} \mathrm{ha}^{-1}$ e 4950,02 $\mathrm{kg} \mathrm{ha}^{-1}$, para dose de máxima eficiência técnica de $0,82 \mathrm{~L} \mathrm{ha}^{-1}$.

O aumento na produtividade pode ser explicado devido a presença de zinco no adubo foliar, pois este elemento possui grande importância no metabolismo das plantas pois está envolvido em vários processos enzimáticos atuando como ativador de várias enzimas atuando em processos como a fotossíntese, produção de amido, fito-hormônios, além de atuar síntese de proteínas e no crescimento meristemático estando ligado diretamente na produção do aminoácido triptofano que é precursor do ácido indolilacético, um hormônio de crescimento que promove o alongamento celular diferencial (Pes \& Arenhardt, 2015).

Na Figura 1 observa-se que houve um aumento na massa de mil grãos até a dose de 0,59 L ha-1 dose de máximo MMG e após esse pico houve queda da massa de acordo com o aumento das doses. Bresson et al. (2018) utilizando cinco doses de zinco $(0,100,200,400$ e 800 g ha-1) não observou ajuste significativo pelas análises de regressão, segundo os autores a ausência de diferença estatística entre as doses foi devido aos teores de zinco no solo estarem adequados $\left(15 \mathrm{mg} \mathrm{dm}^{-3}\right)$.

Fernandes et al. (2007) trabalharam com aplicação foliar de manganês, verificaram que a massa de 1000 grãos obteve uma influência linear de acordo com o aumento nas doses de manganês via foliar. Com aumento das doses de manganês os autores observaram que houve aumento no peso dos grãos em até 8,8\% quando comparados com a testemunha. Esse fato pode ser explicado devido a grande importância que o manganês possui para as plantas, participando na ativação de diversas 
enzimas no processo fotossintético da planta, em particular, as descarboxilases e as desidrogenases envolvidas no ciclo do ácido cítrico (Ciclo de Krebs) além de conseguir acelerar o processo de germinação das sementes, aliado a isso traz ainda aumento na disponibilidade de fósforo e de cálcio para as plantas. Nas leguminosas também possui grande importância por participar do processo de fixação biológica de nitrogênio (Pes \& Arenhardt, 2015).

Figura 1. Efeito de abução foliar com Grain-Set na massa de mil grãos no feijoeiro comum cultivar Pérola.

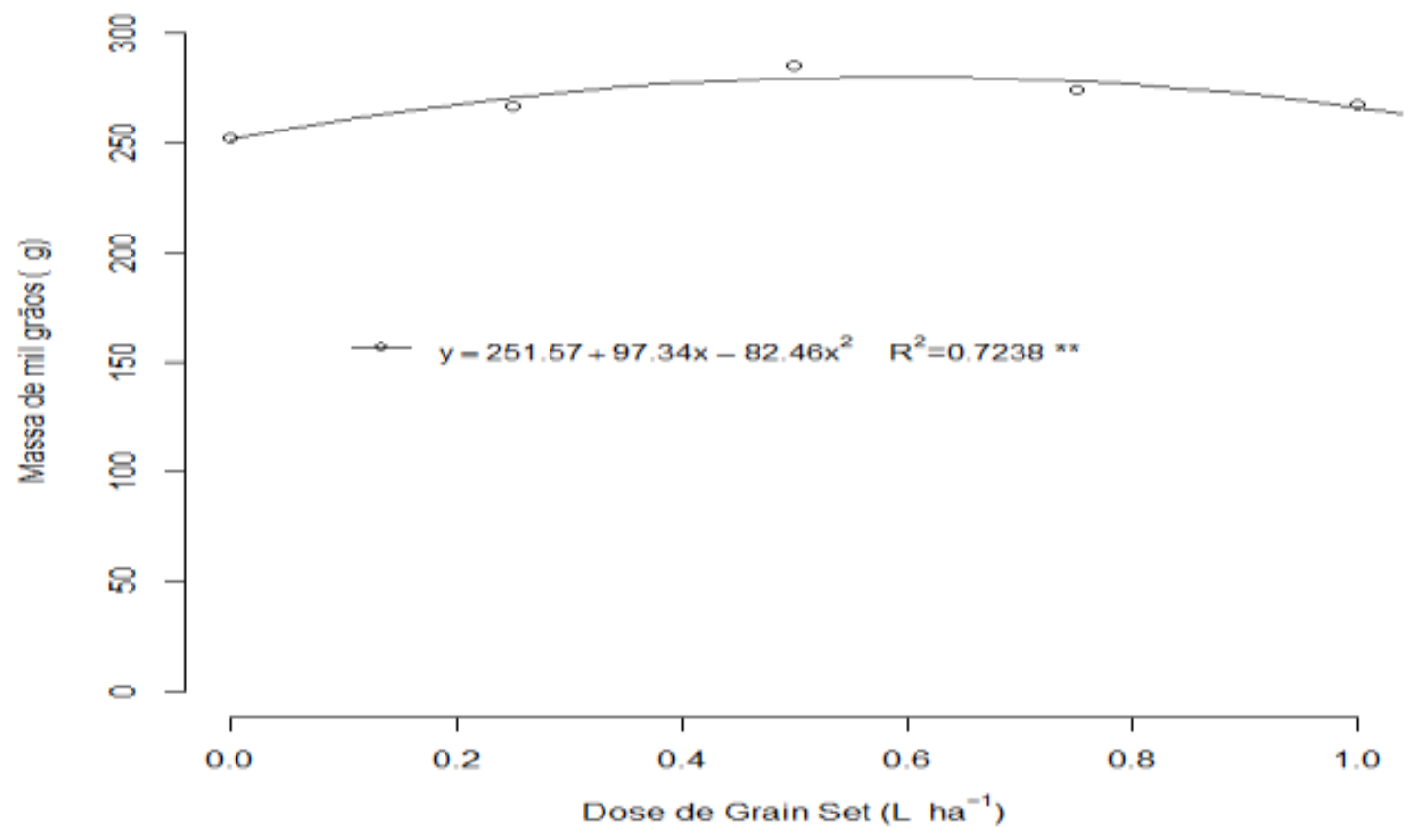

Fonte: Arquivo Pessoal.

Teixeira et al. (2004), estudando clorofila em plantas de feijoeiros, com aubação de manganês e zinco, observaram que os teores de clorofila foram influenciados pelo manganês, havendo efeito no teor de clorofila com a dose de 291,40 $\mathrm{g} \mathrm{ha}^{-1}$, comparadas com a testemunha, isso ocorre devido esse nutriente estar internamente ligado com a composição da molécula de clorofila. Já para aplicação da maior dose mostrou que houve prejuízos ao metabolismo normal da clorofila.

$\mathrm{Na}$ Figura 2 pode se observar que a produtividade máxima obtida foi com a doses de $0,82 \mathrm{~L} \mathrm{ha}^{-1}$, conforme derivação da equação de segundo grau. No trabalho desenvolvido por Bresson et al. (2018) com aplicação de doses de zinco no feijoeiro e não encontraram diferença significativa para a aplicação de zinco foliar no estádio fenológico V3. Para Valeriano et al. (2019) observaram que a MMG foram influenciadas quando utilizaram a dose de $105 \mathrm{~g}^{-1}{ }^{-1}$ de manganês, cuja aplicação foi realizada aso 25 e 35 dias após a emergência. 
Figura 2. Efeito de adubação foliar com Grain-Set na produtividade de feijão comum cultivar Pérola.

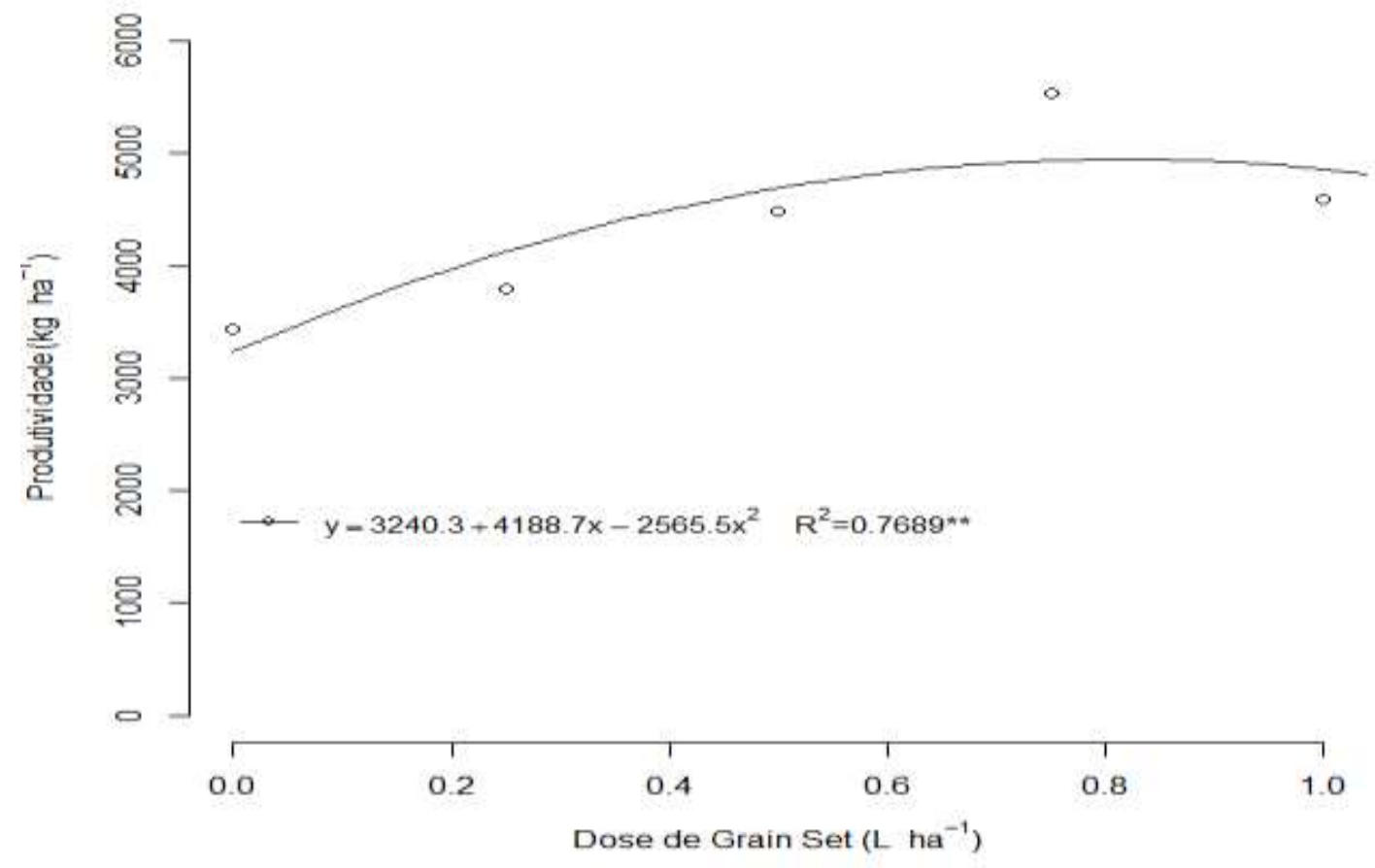

Fonte: Arquivo Pessoal.

A quantidade de nutrientes para as plantas deve ser adequada, pois em quantidades inadequadas podem causar distúrbios nutricionais. A deficiência de zinco nas plantas, pode causar redução do crescimento dos entrenós, as folhas podem ficar pequenas e retorcidas e com isso acarreta diminuição na produção do ácido 3 - indolacético (AIA) auxina. A deficiência de manganês por sua vez causa clorose entre as nervuras das folhas, podendo ocorrer tanto nas folhas mais novas quanto nas mais velhas (Taiz, et al, 2017).

O enxofre também possui grande importância pois está envolvido nos processos estruturais de aminoácidos e vitaminas, nos processos fotossintéticos, respiratórios, produção de amido e também nas clorofilas (Pes \& Arenhardt, 2015).

Teixeira et al. (2003), verificaram que a adubação foliar com manganês e zinco promoveram aumentos lineares nos teores foliares de manganês e zinco, essa implementação das doses trouxe acréscimos nos teores de nitrogênio, cálcio, magnésio, boro e ferro.

Andrade (2016), trabalhando com nutrição foliar de biorreguladores vegetais na cultura do feijão, verificou que a dose de 106,4 $\mathrm{g} \mathrm{ha}^{-1}$ de manganês obteve maior produtividade com $3360 \mathrm{~kg} \mathrm{ha}^{-1}$. Valeriano et al. (2019) observaram produtividades de $5658,72 \mathrm{~kg} \mathrm{ha}^{-1}$ de grãos com aplicação de $105 \mathrm{~g} \mathrm{ha}^{-1}$ de manganês.

A adubação foliar possui algumas vantagens agronômicas podendo ajudar na diminuição entre a aplicação e a absorção pela planta, sendo importante para a fase de crescimento rápido da planta. A absorção de nutrientes pelas folhas é eficaz quando aplicada quantidades corretas para a cultura (Taiz et al., 2017).

\section{Conclusão}

A aplicação de adubo foliar no estádio reprodutivo R5 proporciona maior número de vagens por plantas. Para as variáveis massa de mil grãos e produtividade o uso de fertilizante foliar promove ganhos de massa. 
A dose de $0,59 \mathrm{~L} \mathrm{ha}^{-1}$ para massa de mil grãos promove maior massa $(285,40 \mathrm{~g})$ e a dose de $0,82 \mathrm{~L} \mathrm{ha}^{-1}$, proporciona maior produtividade.

\section{Referências}

Andrade, G. H. P. (2016). Nutrição foliar e uso de biorreguladores vegetais na cultura do feijão. Curso agronomia UFMT- Mato grosso- Sinop. https://bdm.ufmt.br/bitstream/1/752/1/TCC-2016 GABRIEL\%20HENRIQUE\%20PINHEIRO\%20ANDRADE.pdf.

Bevilaqua, G. A. P., Silva Filho, P. M., Possenti, J. C. (2002). Aplicação foliar de cálcio e boro e componentes de rendimento e qualidade de sementes de soja. Ciência Rural, v. 32, n. 1, p. 31-34. scielo.br/pdf/cr/v32n1/a06v32n1.pdf.

Bresson, J.B., Zanão Júnior, L.A., Miola, V., Andrade, E.A., Rotta, L.I. (2018). Aplicação de zinco via foliar na cultura do feijoeiro. Revista Cultivando o Saber, edição especial, p.81-87.

Carvalho, N. M., Nakagawa, J. (2000). Sementes: ciência, tecnologia e produção. 4 ed. Jaboticabal: FUNEP, 588p.

Conab - Acompanhamento da safra brasileira Grãos. (2021). Safra 2020/21 - oitavo levantamento, Brasília, 5 (8), 1-115. https://www.conab.gov.br/infoagro/safras/graos/boletim-da-safra-de-graos.

Crusciol, C. A. C., Soratto, R. P., Silva, L. M. da, Lemos, L. B. (2006). Aplicação de enxofre em cobertura no feijoeiro em sistema de plantio direto. Bragantia, v.65 n.3, p.459-465. https://www.scielo.br/pdf/brag/v65n3/a12v65n3.pdf.

Embrapa Soja. (2013). Tecnologias de produção de soja - Região Central do Brasil 2014. - Londrina: Embrapa Soja, $1^{\circ}$ ed, nº $16,265 p$. ISSN $2176-2902$. https://ainfo.cnptia.embrapa.br/digital/bitstream/item/95489/1/SP-16-online.pdf.

Embrapa. (2018). Conhecendo a Fenologia do Feijoeiro e Seus Aspectos Fitotécnicos. - Brasília: Embrapa Arroz e Feijão, $1^{\circ}$ ed, n 16 , 265p. ISSN 21762902. https://ainfo.cnptia.embrapa.br/digital/bitstream/item/173690/1/CNPAF-2018 lvfeijoeiro.pdf.

Epstein, E., Bloom, A. J. (2006). Nutrição mineral de plantas: princípios e perspectivas. Londrina - PR: Editora Planta. https://www.agrolink.com.br/downloads/nutri\%C3\%A7\%C3\%A3o\%20mineral\%20de\%20plantas\%20-\%20princ\%C3\%ADpios\%20e\%20conceitos.pdf.

Fernandes, D., Soratto, R. P. S, Kulcznski, S. M, Biscaro, G. A; Reis, C. J. (2007). Produtividade e qualidade fisiológica de sementes de feijão em conseqüência da aplicação foliar de manganês. Pesquisa agropecuária Brasileira. v.42 n.3 Brasília Mar. doi: https://doi.org/10.1590/S0100204X2007000300016

Frasca, L. L. de., Nascente, A. S., Lanna, A. C., Carvalho, M. C. S., Costa, G. G. (2020). Bioestimulantes no crescimento vegetal e desempenho agronômico do feijão comum de ciclo superprecoce. Revista Agrarian. v.13, n.47, p.27-41, Dourados. https://ainfo.cnptia.embrapa.br/digital/bitstream/item/211854/1/35745.pdf.

Furtini Neto, A. E., Fernandes, L. A. Faquin, V., Silva, I. R. da., Accioly, A. M. de., A. (2000). Resposta de cultivares de feijoeiro ao enxofre. Pesquisa agropecuária brasileira, v.35, n.3, p.567-573. https://www.scielo.br/pdf/pab/v35n3/v35n3a12.pdf.

Malavolta, E. (2006). Manual de nutrição mineral de plantas. São Paulo: Editora Agronômica Ceres, 638p.

Marschner, H. (1995). Mineral nutrition of higher plants. 2. ed. San Diego: Academic Press, 889p.

Marschner, P. (2012). Marschner's mineral nutrititon of higher plants.3ed. Academic Press, 649 p.

Oliveira, C. A. B., Pelá, G. M., Pelá, A. (2017). Inoculação com Rhizobium tropici e adubação foliar com Molibdênio na cultura do feijão comum. Revista de Agricultura Neotropical, Cassilândia-MS, v. 4, Suplemento 1, p. 43-50, dez. ISSN 2358-6303. https://www.researchgate.net/profile/AdilsonPela/publication/322528591_Inoculacao_com_Rhizobium_tropici_e_adubacao_foliar_com_molibdenio_na_cultura_do_feijao_comum/links/5a5e3f710f7e9b4 f783ba4e0/Inoculacao-com-Rhizobium-tropici-e-adubacao-foliar-com-molibdenio-na-cultura-do-feijao-comum.pdf.

Oliveira, I. B., Mendonça, G. W., Binotti. F. F. S.; Ascoli, A. A., Costa, E. (2015). Fertilizante foliar em feijoeiro de inverno e sua influência na produtividade e qualidade fisiológica das sementes. Revista de Agricultura Neotropical, Cassilândia-MS, v. 2, n. 2, p. 57-67. https://periodicosonline.uems.br/index.php/agrineo/article/view/262.

Pes, L., Arenhardt, Z. M. H. (2015). Fisiologia Vegetal - Santa Maria, RS: Universidade Federal de Santa Maria, Colégio Politécnico, Rede e-Tec Brasil. https://www.ufsm.br/app/uploads/sites/342/2020/04/FISIOLOGIA-VEGETAL.pdf.

Prado, R. M., Frade Junior, E. F., Mouta, E. R., São João, A. C. G., Costa, R. S. S. (2007). Crescimento inicial e estado nutricional do trigo submetido à aplicação de zinco via semente. Revista de la Ciência del Suelo y Nutrición Vegetal, Temuco, v. 7, n. 2, p. 22-31. doi: http://dx.doi.org/10.4067/S071827912007000200003 .

Rosolem, C. A., Marubayashi, O. M. (1994). Seja o doutor do seu feijoeiro. Piracicaba: POTAFOS, p.1-4.

Silva, O. F. da., Wander, A. E. (2013). O feijão comum no Brasil passado, presente e futuro. Santo Antônio de Goiás-GO: Embrapa Arroz e Feijão. (Embrapa Arroz e Feijão. Documentos, 287). https://www.infoteca.cnptia.embrapa.br/infoteca/bitstream/doc/961699/1/seriedocumentos287.pdf.

Taiz, L., Zeiger, E., Moller, I. M., Murphy, A. (2017). Fisiologia e desenvolvimento vegetal, $6 . \quad$ ed. Porto Alegre: Artmed. https://grupos.moodle.ufsc.br/pluginfile.php/474835/mod_resource/content/0/Fisiologia\%20e\%20desenvolvimento\%20vegetal\%20-

\%20Zair\%206\%C2\%AAed.pdf. 
Research, Society and Development, v. 10, n. 10, e388101018830, 2021

(CC BY 4.0) | ISSN 2525-3409 | DOI: http://dx.doi.org/10.33448/rsd-v10i10.18830

Teixeira, I. R., Bórem, A., Andrade, M. J. B., Giúdice, M. P. D., Cecon, P. R. (2004). Teores de clorofila em plantas de feijoeiros influenciadas pela adubação com manganês e zinco. Revista Acta Scientiarum Agronomy. Maringá, v. 26, no. 2, p. 147-152. doi: https://doi.org/10.4025/actasciagron.v26i2.1876.

Teixeira, I. R., Borém, A., Araujo, A. de A., Fontes, R. L. F., Mota, J. H., SILVA, A. G. (2003). Nutrição mineral do feijoeiro em função de doses de manganês e zinco. Revista Semina: Ciências Agrárias, Londrina, v. 24, n. 2, p. 235-242, jul./dez. Recuperado de: http://www.unicentroagronomia.com/imagens/noticias/dissertacao_final_wagner_kachinski.pdf. Acesso em: 24 de fevereiro de 2021.

Valeriano, T.T.B., Silva Neto, O.F., Borges, R.M., Santana, M.J., Silva, K.A. (2019). Turnos de rega e adubações foliares com produtos comerciais de fontes de micronutrientes na cultura do feijoeiro. Revista Inova Ciência \& Tecnologia, v.5, n.2, p.5-11. 